\title{
RNA interference mediates RNA toxicity with parent-of-origin effects in C. elegans expressing CTG repeats
}

\author{
Maya Braun ${ }^{1}$, Shachar Shoshani ${ }^{1}$, Joana Teixeira ${ }^{2}$, Anna Mellul Shtern ${ }^{1}$, Maya Miller ${ }^{1}$, Zvi Granot ${ }^{1}$, \\ Sylvia E J Fischer ${ }^{3}$, Susana M D A Garcia ${ }^{2 *}$, Yuval Tabach ${ }^{1^{*}}$ \\ ${ }^{1}$ Department of Developmental Biology and Cancer Research, Institute for Medical Research Israel- \\ Canada, Hebrew University of Jerusalem Jerusalem, Israel. \\ ${ }^{2}$ Institute of Biotechnology, HiLIFE, University of Helsinki, Helsinki, Finland. \\ ${ }^{3}$ Division of Infectious Diseases, Boston Children's Hospital, Harvard Medical School, Boston, MA, \\ USA. \\ *Corresponding authors
}

Key words: epi-genetic inheritance, C. elegans, small RNA pathway, CUG repeats, RNA interference

\begin{abstract}
Nucleotide repeat expansions are a hallmark of over 40 neurodegenerative diseases. These repeats cause RNA toxicity and trigger multisystemic symptoms that worsen with age. RNA toxicity can trigger, through an unclear mechanism, severe disease manifestation in infants that inherited repeats from their mothers. Here we show in Caenorhabditis elegans how RNA interference machinery causes intergenerational toxicity through inheritance of siRNAs derived from CUG repeats. The maternal repeat-derived small RNAs cause transcriptomic changes in the offspring, reduce motility and shorten lifespan. However, the toxicity phenotypes in the offspring can be rescued by perturbing the RNAi machinery in affected mothers. This points to a novel mechanism linking maternal bias and the RNAi machinery and suggests that toxic RNA is transmitted to offspring and causes disease phenotypes through intergenerational epigenetic inheritance.
\end{abstract}

Abbreviations: DM1, myotonic dystrophy type 1; DMPK, dystrophia myotonica-protein kinase gene; EV, empty vector (control RNAi); OP50, E. coli strain; RNAi, RNA interference; 3'UTR, 3' untranslated region; wt, wild type 


\section{Introduction}

Over 40 genetic diseases are caused by an expansion of a short nucleotide repeat sequence in the genome ${ }^{1}$. RNAs transcribed from the expanded regions were shown to disrupt cellular function through a gain-of-function or loss-of-function type of mechanisms, causing RNA toxicity. Included in the gain-of-function mechanisms are sequestration of RNA-binding proteins, microRNA and siRNA dysfunction, and RAN translation ${ }^{2-6}$.

Several repeat-based disorders exhibit a correlation between disease severity and gender of the transmitting parent, also known as the parent-of-origin effect ${ }^{7-9}$. Maternal bias is observed in myotonic dystrophy type 1 (DM1), the most common form of adult-onset muscular dystrophy, an autosomal dominant neuromuscular disease ${ }^{10,11}$. DM1 is caused by an unstable CTG repeat expansion in the $3^{\prime}$ untranslated region (3'UTR) of a serine-threonine protein kinase gene, DMPK. In healthy individuals the DMPK gene contains 5-37 CTG repeats, whereas DM1 patients bear a range of 50 to several thousand repeat expansions ${ }^{12}$. Patients present a variety of symptoms but are mainly characterized by muscle dysfunction, progressive muscle wasting, atrophy, and myotonia. DM1 is classified into five subtypes based on repeat length and age of onset, marking congenital myotonic dystrophy as exceptional in parameters of severity and pathophysiology of the disease. In contrast to the other subtypes that are characterized by late onset and progressive diseases, in congenital DM1 the symptoms already appear during pregnancy, with infants displaying upon birth severe generalized weakness and respiratory insufficiency. The newborns suffer from life-threatening complications and display up to $40 \%$ mortality ${ }^{8}$. Contrary to expected deterioration over time, symptoms improve during childhood until adult-onset DM1 symptoms develop during adolescence ${ }^{13}$. Congenital myotonic dystrophy is almost exclusively of maternal transmission ${ }^{14,15}$. Comparison of parental inheritance shows generally worse outcomes in DM1 children born to affected mothers ${ }^{16}$. Moreover, non-DM1 carrier children born to DM1 mothers show a worse medical prognosis following pre-implantation genetic diagnosis ${ }^{17,18}$. Together, these data demonstrate a clear gender bias. While DM1 is the best characterized disease, additional expansion repeat disorders presenting an early-onset form with distinct clinical features include Huntington's Disease-like 2 (HDL2) and spinocerebellar ataxia type 8 (SCA 8$)^{7,19,20}$. Both are caused by CUG repeats in the 3'UTR, suggesting a global mechanism driven by the toxic CUG RNAs. 
The mechanism underlying this parent-of-origin toxic effect remains unclear. Upstream $\mathrm{CpG}$ methylation was linked with maternal bias for transmission ${ }^{21}$, however it does not account for the different disease phenotypes observed. Possible factors such as extended maternal repeat length, mitochondrial DNA mutations or maternal intrauterine factors have not been identified $^{22-26}$ thus implying that the contribution of additional factors should be considered $^{14,27}$.

RNA interference (RNAi) is a conserved gene-silencing mechanism that plays important roles in regulation of viruses, transposons and genes ${ }^{28}$. Genetic and biochemical analyses revealed numerous proteins (such as Argonaute and Dicer) as essential cofactors that process and present small RNAs to their targets ${ }^{29-35}$. The enzyme Dicer processes trigger double-stranded RNA (dsRNA) into short-interfering RNA (siRNA) of $\sim 21$ nucleotides. These form a protein-RNA complex that degrades and inhibits translation of the target messenger RNA (mRNA) bearing a complementary sequence ${ }^{36}$. Systematic analysis of the RNAi pathway revealed conservation and co-evolution of the associated proteins across eukaryotes ${ }^{31}$. Many of the early discoveries in the field ${ }^{32,34,35,37-43}$ were established in Caenorhabditis elegans nematodes due to the availability of unique genetic tools that allowed mapping and characterization of the RNAi pathway.

The RNAi machinery is also associated with various pathological states ${ }^{44-46}$. Specifically, it was found to contribute to the aberrant activation of pathogenic RNA toxicity mechanisms in nematodes ${ }^{47}$, drosophila ${ }^{48}$, and mammals ${ }^{49-51}$. Expanded DNA repeats, when transcribed, tend to form stable hairpins that accumulate as RNA foci in the nucleus and cytoplasm ${ }^{4,52-54}$. Dicer can target these double-stranded RNAs with an imperfect pairing and cleave them to siRNAs ${ }^{50,51,55,56}$. These repeat-derived siRNAs engage the downstream RNAi silencing pathway and cause global changes in the expression of endogenous genes bearing complementary sequences ${ }^{47}$.

The RNAi machinery also mediates heritable epigenetic modulations, a phenomenon termed RNAi inheritance ${ }^{57-68}$. siRNAs are inherited from parent to progeny through oocytes and potently prompt transgenerational gene silencing ${ }^{64}$. Recently, a maternal parent-of-origin effect was observed in the transmission of small RNA-based endoderm development phenotypes and RNAi machinery defects ${ }^{57,69,70}$. In mammals, the presence of small RNAs from maternal origin was shown in human and mouse cord blood ${ }^{71-75}$. 
Here, we use $C$. elegans to uncover the mechanisms that underlie the parent-of-origin RNA toxicity effect. We hypothesize a key role for the RNAi machinery in these pathogenic processes. Using nematodes has the advantage of providing an isogenic system to address these mechanisms in animals, which enables efficient perturbation of investigated genes and consequent examination of phenotypic, developmental, and cross-generational changes. We recapitulate a maternal bias in a $C$. elegans model expressing expanded CUG repeats and show that disrupting the RNAi pathway in affected mothers rescues toxicity in offspring. Overall, our work points to the central role of the RNAi pathway as the underlying mechanism of the parent-of-origin effect present in RNA repeat-based pathogenesis.

\section{Results}

\section{In vivo isogenic model for studying phenotypes of long RNA repeats}

We adapted a C. elegans experimental system ${ }^{47}$ to identify the mechanisms underlying parentof-origin toxicity associated with CUG repeat expansions, specifically the potential role of RNAi machinery in these toxic processes. We used $C$. elegans strains expressing GFP containing either 0 or $123 \mathrm{CTG}$ repeats (0CUG and 123CUG, respectively) in the 3'UTR, under the regulation of the myo-3 muscle-specific promotor (Fig. 1A) ${ }^{47,52}$. Expression of 123CTG repeats was shown to be sufficient to induce RNA toxicity in mammalian myocytes and nematodes, whereas longer repeat lengths resulted in embryonic lethality ${ }^{47,52,76}$. To exacerbate the toxicity induced by the repeat-bearing RNAs, transgenic strains were generated expressing several copies of the repeats as an extrachromosomal array integrated in the genome (see Discussion).

To reconfirm the robustness of the model, we quantified the baseline toxicity of the expanded repeats ${ }^{47}$. We conducted a motility assay and measured the speed of movement of the nematodes using video recording under light microscopy at three different ages $\left(2^{\text {nd }}, 4^{\text {th }}\right.$, and $6^{\text {th }}$ day of adulthood). The average moving speed of 0CUG nematodes was $0.231 \mathrm{~mm} / \mathrm{s}, 0.21$ $\mathrm{mm} / \mathrm{s}$, and $0.199 \mathrm{~mm} / \mathrm{s}$ at 2, 4, and 6-day-old adults. 123CUG animals moved at an average speed of $0.209 \mathrm{~mm} / \mathrm{s}, 0.178 \mathrm{~mm} / \mathrm{s}$, and $0.164 \mathrm{~mm} / \mathrm{s}$ at 2, 4, and 6-day-old adults, exhibiting impaired motility that deteriorated with age (Fig. 1B $)^{47}$. Next, we examined how the repeats affect susceptibility to stress. We exposed wild type, 0CUG, and 123CUG nematodes to heat shock $\left(35^{\circ} \mathrm{C}\right)$ and scored for viability every two hours. 123CUG animals showed a higher susceptibility to heat stress ( $\mathrm{p}<0.01$, Fig. 1C). 


\section{Maternal inheritance of CUG repeats enhances motility impairment and susceptibility to stress}

To investigate the parent-of-origin effect, we assessed toxicity in offspring with either maternal or paternal inheritance of repeats. We generated 123CUG males and hermaphrodites. We crossed 123CUG males with wild type hermaphrodites and 123CUG hermaphrodites with wild type males to assess paternal (Paternal 123CUG) and maternal (Maternal 123CUG) transmission of repeats, respectively (Fig. 1D). The 123CUG animals did not show changes in repeat size in successive generations (Table 1S). Thus, the Maternal and Paternal 123CUG offspring share the same genetic background, expressing transcripts with the same repeat length (heterozygous 123CUG). Next, to determine whether differences in toxicity were present, we performed motility and heat stress assays and compared the two groups.

Maternal inheritance of repeats resulted in severely impaired motility. Animals showed an average moving speed of $0.188 \mathrm{~mm} / \mathrm{s}$ in two-day-old Maternal 123CUG adults as compared with $0.225 \mathrm{~mm} / \mathrm{s}$ in the 0CUG group $(\mathrm{p}<0.0001)$. Importantly, the motility of animals with paternal inheritance of toxic repeats was indistinguishable from the 0CUG controls, with a speed of $0.22 \mathrm{~mm} / \mathrm{s}$ (Fig. 1E). We then tested these animals for changes in motility with aging and observed an age-dependent gradual loss of motility.

The Maternal 123CUG animals displayed speeds ranging from $0.188 \mathrm{~mm} / \mathrm{s}$ to $0.125 \mathrm{~mm} / \mathrm{s}$ from the $2^{\text {nd }}$ to the $6^{\text {th }}$ day of adulthood, respectively. Thus we chose two-day-old adults for the following assays as they have a strong phenotype and are less susceptible to confounding environmental factors. Next, to check whether the maternal bias is reproduced in additional phenotypes, we exposed the animals to heat shock (Fig. 1F). Maternal 123CUG nematodes were significantly more susceptible to heat stress, with survival rates of $55 \%$ after six hours as compared with $80 \%$ in the control groups. After eight hours, only 5\% of Maternal 123CUG nematodes survived as compared with $18 \%$ of Paternal $123 \mathrm{CUG}$ and over $30 \%$ in the control groups. Based on the hypothesis of asymmetric inheritance of toxicity, we tested whether an effect on normal nematode growth was present. We assessed nematode morphology and found that the Maternal $123 \mathrm{CUG}$ animals were significantly shorter at the $1^{\text {st }}$ larval stage, with an average length of $173.2 \mu \mathrm{m}$ as compared with $187.5 \mu \mathrm{m}$ in the 0 CUG animals $\left(\mathrm{p}=1.83 * 10^{-6}\right)$. Notably, the length of the Paternal 123CUG nematodes was similar in size as the 0CUG controls. Aging led to a reduction in the gap - the length was $1327 \mu \mathrm{m}$ in two-day-old adults Maternal 123CUG as compared with $1368 \mu \mathrm{m}$ in Paternal 123CUG and $1382 \mu \mathrm{m}$ in 0CUG $(\mathrm{p}=0.002$, Fig. 1S). To eliminate a possible strain-specific bias, which might result from the 
bioRxiv preprint doi: https://doi.org/10.1101/2021.05.19.444826; this version posted May 19, 2021. The copyright holder for this preprint (which was not certified by peer review) is the author/funder, who has granted bioRxiv a license to display the preprint in perpetuity. It is made available under aCC-BY-NC-ND 4.0 International license.
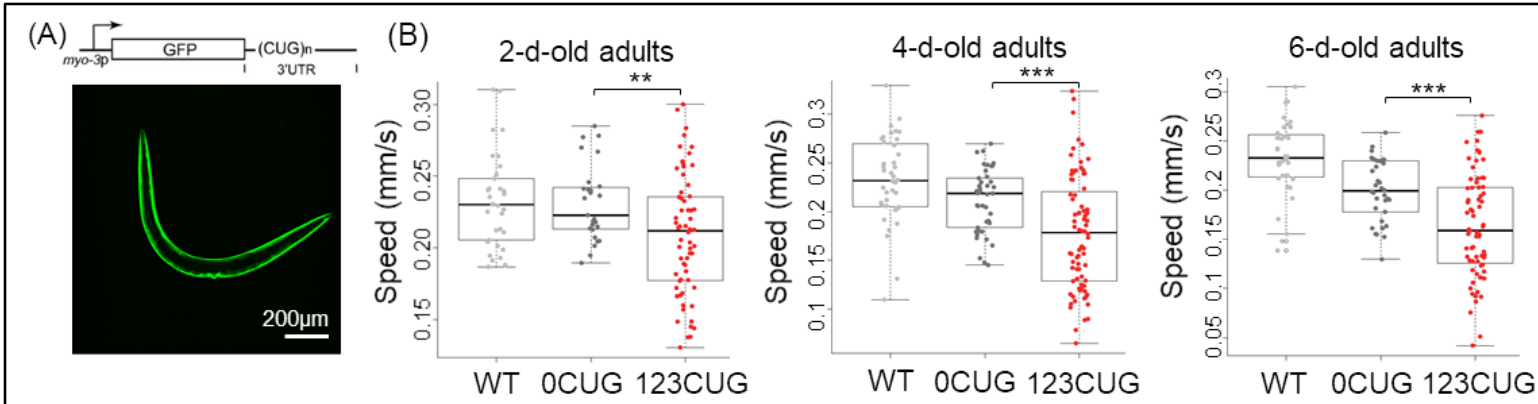

(C)

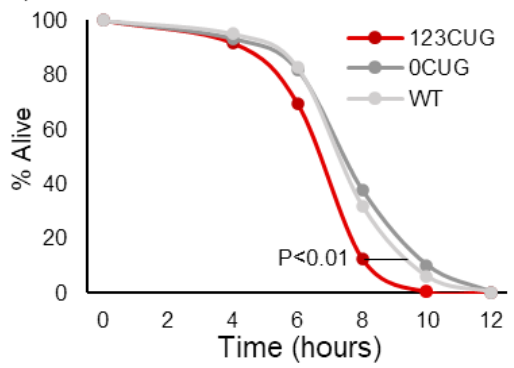

(D)

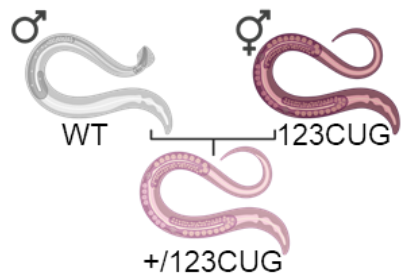

Maternal $123 \mathrm{CUG}$

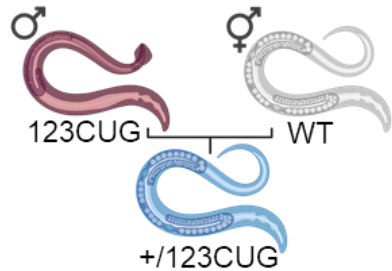

Paternal $123 \mathrm{CUG}$
$(\mathrm{E})$

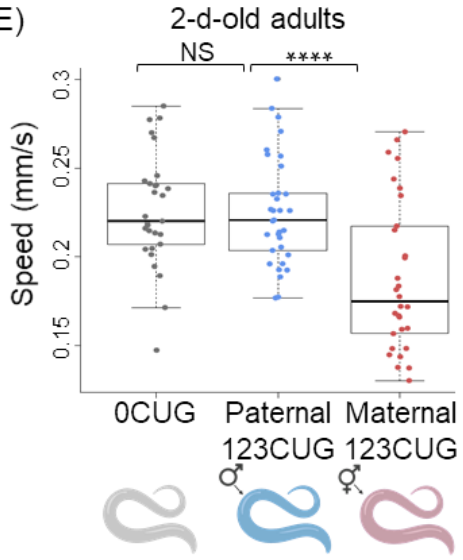

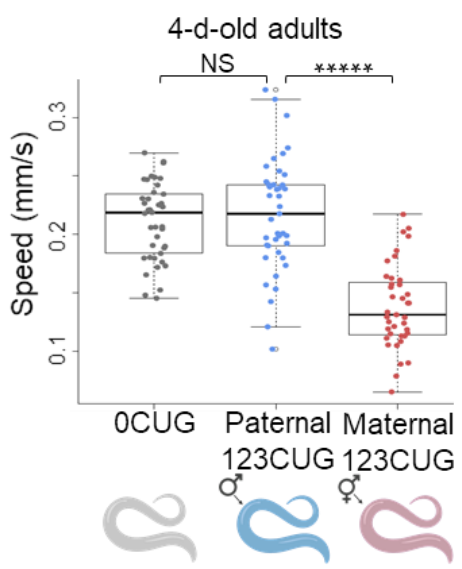

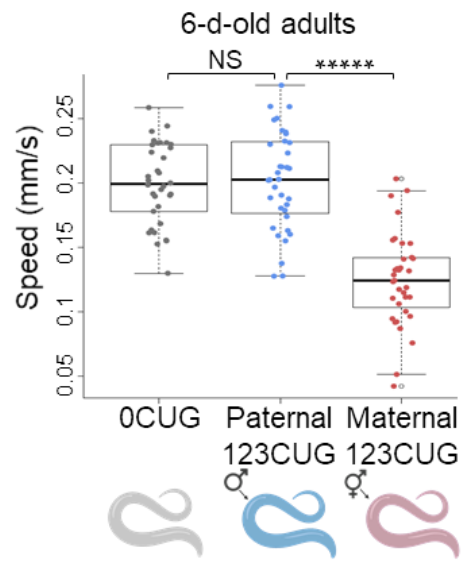

$(\mathrm{F})$

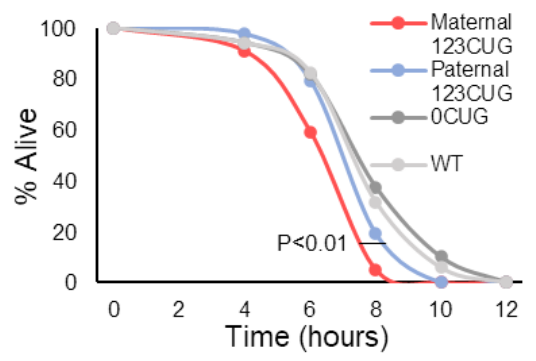

Figure 1: Maternal inheritance of repeats aggravates disease phenotype. (A) C. elegans model for repeat expansions. 123 CUG repeats are expressed in the 3'UTR of GFP under the myo-3 promoter. Representative image of a 123CUG nematode. (B) Motility assay (moving speed) of WT, 0CUG, and 123CUG nematodes ( $\mathrm{n}=60$ ) for two-, four-, and six-day-old adults. (C) Survival curve of WT, 0CUG, and 123CUG day one adult nematodes following heat shock $\left(35^{\circ} \mathrm{C}, \mathrm{n}=80\right)$. (D) A general scheme of the parent-of-origin experimental system. (E) Motility assay for assessment of parent-of-origin effects. Moving speed of 0CUG, paternally inherited $123 \mathrm{CUG}$, and maternally inherited $123 \mathrm{CUG}$ nematodes ( $\mathrm{n}=45$ ). (F) Survival curve of Maternal $123 \mathrm{CUG}$ and Paternal $123 \mathrm{CUG}$ animals following heat shock $\left(35^{\circ} \mathrm{C}\right.$, $\mathrm{n}=80$ ). In the motility assays (B and $\mathrm{E}$ ), the average of three biological replicates is represented. Data are represented as a mean \pm SD and significance was calculated using a one-tailed Student's $t$ test. In the heat shock assays (C and F), the results shown are from a representative experiment of three biological replicates. Statistical analyses were performed using log-rank (Mantel-cox) and Gehan-Breslow-Wilcoxon tests. ${ }^{*} \mathrm{p}<0.05 ; * * \mathrm{p}<0.01 ; * * \mathrm{p}<0.001 ; * * * \mathrm{p}<0.0001$; NS - not significant. 
location site of repeat integration in the genome or an uncontrolled evolutionary effect such as selection or random drift, we repeated the motility experiment with different 0CUG and 123CUG strains (GR3208 and GR3207, respectively). These experiments supported the previous results and exhibited an enhanced maternal effect (Fig. 2S).

\section{Maternal inheritance of repeats suppresses gene expression of genes bearing endogenous CTG- and CAG- repeats}

Across species, transcribed CUG- and CAG-repeats trigger abnormal gene silencing induced by the RNA interference $e^{47,50,51}$. In both humans and C. elegans expressing expanded repeats, silencing was specifically enriched in genes bearing complementary short repeat sequences, a hallmark of silencing by the RNAi machinery ${ }^{47}$. We aimed to test whether the RNAi pathways play a role through a similar mechanism in the parent-of-origin toxicity effect.

First, we determined that the CUG repeats were targeted by the RNAi machinery and processed to siRNAs. We measured the levels of siRNAs comprised of seven CUG repeats in Paternal 123CUG and Maternal 123CUG two-day-old adult nematodes and compared them with wild type nematodes (see Methods). Both Maternal and Paternal 123CUG animals showed an enrichment of repeat-derived siRNAs (Fig. 3S). Next, we checked if there is a difference in siRNA-dependent silencing between the two groups, suggestive of the involvement of the pathway in parent-of-origin toxicity. We have previously shown through RNAseq transcriptome analysis of $123 \mathrm{CUG}$ animals, that a broad decrease in expression levels is observed in endogenous genes bearing CTG repeats. The expression of these genes was enriched in muscles, neurons, hypodermis, and intestine, correlative to the presented disease phenotypes. Here, we measured the expression levels of 24 potential targetable genes that contained seven or more endogenous CTG or CAG repeats and were previously validated as markers of CTG-targeted silencing ${ }^{47}$. Gene expression was compared between offspring with Maternal and Paternal 123CUG. We collected RNA from the $1^{\text {st }}$ larval stage and two-day-old adult nematodes expressing Maternal 123CUG, Paternal 123CUG, or 0CUG. Using qPCR, we analyzed the expression of the 24 genes. Two-day-old adult Maternal $123 \mathrm{CUG}$ animals showed a significant 4-fold down-regulation in expression, with Paternal 123CUG displaying a 2.6fold reduction, both relative to the 0CUG controls (Fig. 2A-B). These strains were analyzed at a younger developmental stage, i.e. the $1^{\text {st }}$ larval stage, and exhibited a slightly more severe gene silencing phenotype. The Maternal 123CUG group exhibited a 2-fold silencing relative to 0CUG, whereas the Paternal 123CUG group showed a 1.6 down-regulation (Fig. 2A-B). 
(A)

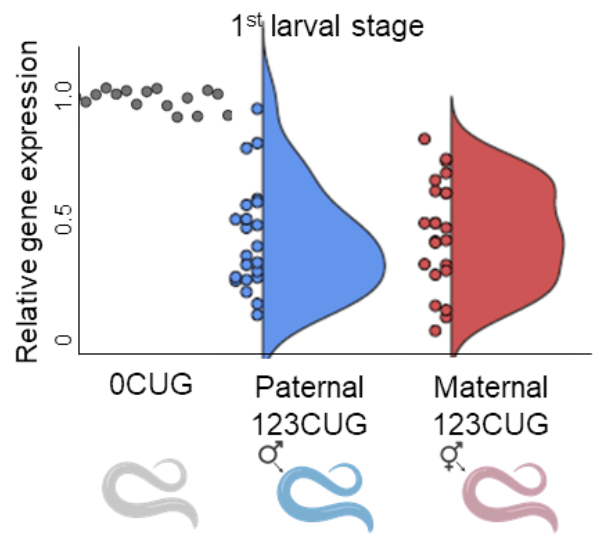

(C)

$$
1^{\text {st }} \text { larval stage }
$$

Paternal OCUG

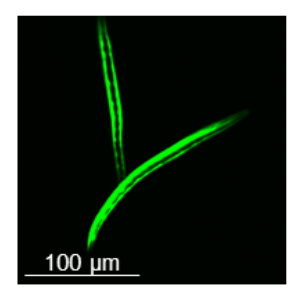

Maternal OCUG

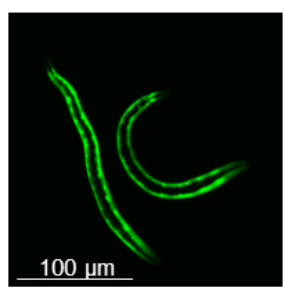

Paternal 123CUG
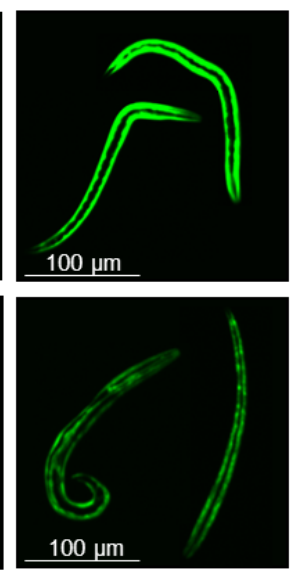

Maternal 123CUG

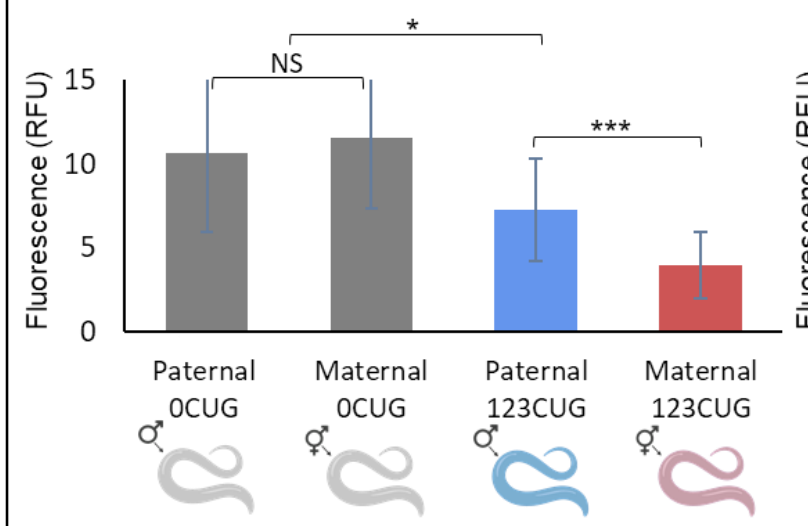

(B)

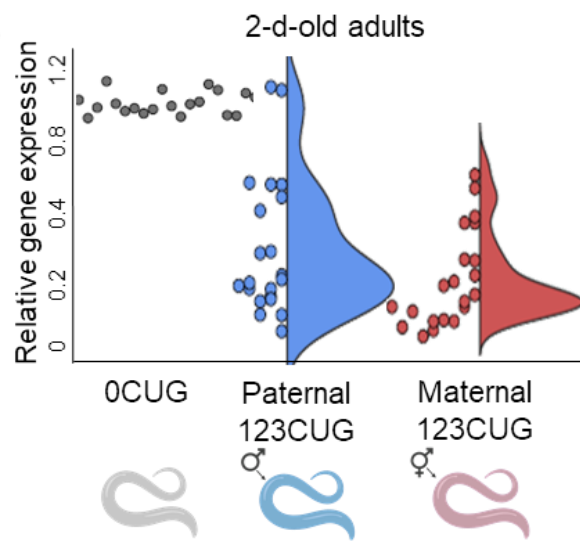

(D)

2-d-old adults

Paternal OCUG Maternal OCUG
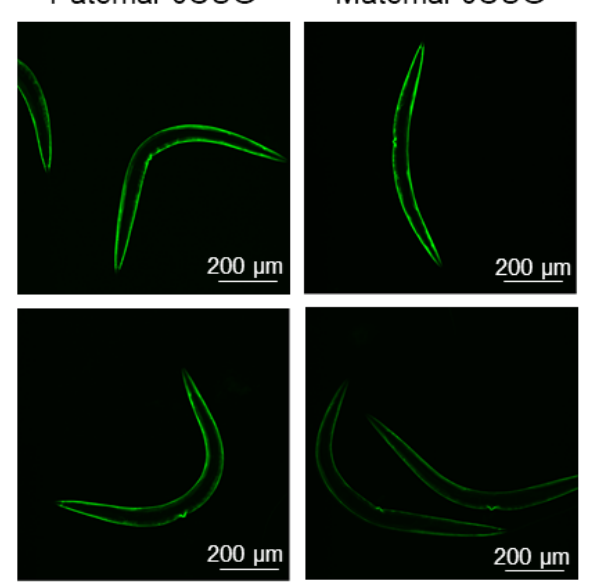

Paternal 123CUG Maternal 123CUG

Figure 2: Maternal inheritance of repeats escalates downregulation in expression of genes bearing endogenous CTG- and CAG- repeats. Gene expression fold change of 24 genes bearing $\geq 7$ CTG/CAG repeats in L1 (A) and 2day-old adults (B), relative to 0CUG. The qPCR is an average of 3 biological experiments and 3 technical replicates. Fluorescence levels of Maternal 0CUG, Paternal 0CUG, Maternal 123CUG, and Paternal 123CUG nematodes in (C) $1^{\text {st }}$ larval stage and (D) 2-day adults. Relative fluorescence was computationally quantified $(\mathrm{n}=50)$ and representative fluorescent microscopy images are shown. Data are represented as a mean $\pm \mathrm{SD}$ of three biological replicates and significance was calculated using a one-tailed Student's t test. $* \mathrm{p}<0.05, * * * \mathrm{p}<0.001$. 
Overall, these genes present stronger repression in progeny with Maternal 123CUG as compared with Paternal 123CUG.

In addition to transcriptomic changes, $123 \mathrm{CUG}$ animals show a noticeable decrease in GFP protein levels with age ${ }^{47,52}$ as compared with $0 \mathrm{CUG}$, which may point to transgene silencing ${ }^{77,78}$. To establish whether the parental origin of repeats causes variability in GFP levels, we measured and compared the fluorescence levels of Maternal 123CUG, Paternal 123CUG, Maternal 0CUG, and Paternal 0CUG nematodes at two different life stages $\left(1^{\text {st }}\right.$ larval stage and two-day-old adults). The Maternal 123CUG animals exhibited a 2-fold stronger decay in fluorescence as compared to the Paternal $123 \mathrm{CUG}$ animals at the $1^{\text {st }}$ larval stage (Fig. 2C). This trend persisted, although attenuated, for two-day-old adults (Fig. 2D). There was no difference between the Maternal 0CUG and Paternal 0CUG strains. Together these data indicate that the RNAi machinery processes the expanded repeats to siRNAs and mediate aberrant silencing of genes bearing complementary sequences.

\section{Directly activating the RNAi pathway by feeding nematodes 50CUG dsRNA recapitulates toxicity phenotypes}

The integrated repeats in the $123 \mathrm{CUG}$ nematodes may have various uncharacterized effects as a consequence of how transgenes are generated in $C$. elegans. Although the previous experiments were repeated in two independent strains, we wished to take a complementary approach in dissecting the explicit effect of the repeats. Consequently, we directly triggered the RNAi machinery using exogenous dsRNA bearing expanded repeats. This approach enables the accurate determination of the phenotypic effects of the repeats, as they serve as direct substrates to the RNAi machinery and therefore exclude other confounders mediating RNA toxicity mechanisms. To this end, we fed wild type animals with bacteria expressing RNAs bearing 50CUG repeats (50CUG RNAi). We assessed three groups: nematodes grown on an empty vector (EV), offspring of hermaphrodites fed 50CUG dsRNA, and nematodes fed 50CUG dsRNA for two generations (Fig. 3A). 
Two generations of 50CUG dsRNA-treated animals (P0 and F1 were treated) and offspring of treated animals (F1 were not treated) all exhibited impaired motility with an average moving speed of $0.166 \mathrm{~mm} / \mathrm{s}$ and $0.168 \mathrm{~mm} / \mathrm{s}$, respectively, as compared with $0.229 \mathrm{~mm} / \mathrm{s}$ in the wild type group grown on $\mathrm{EV}\left(\mathrm{p}=1.18^{*} 10^{-10}\right.$, Fig. 3B). A similar effect of suppression was observed in the expression of the $24 \mathrm{CTG} / \mathrm{CAG}$-containing genes (as defined above). These target genes were down-regulated on average by 3.7 fold in the offspring of 50CUG group, and 3.5 fold in the group that received 50CUG treatment for two generations, relative to the wild type group (Fig. 3C). The offspring of 50CUG dsRNA treated mothers were similarly impaired in animals that were directly treated with dsRNA containing expanded repeats.

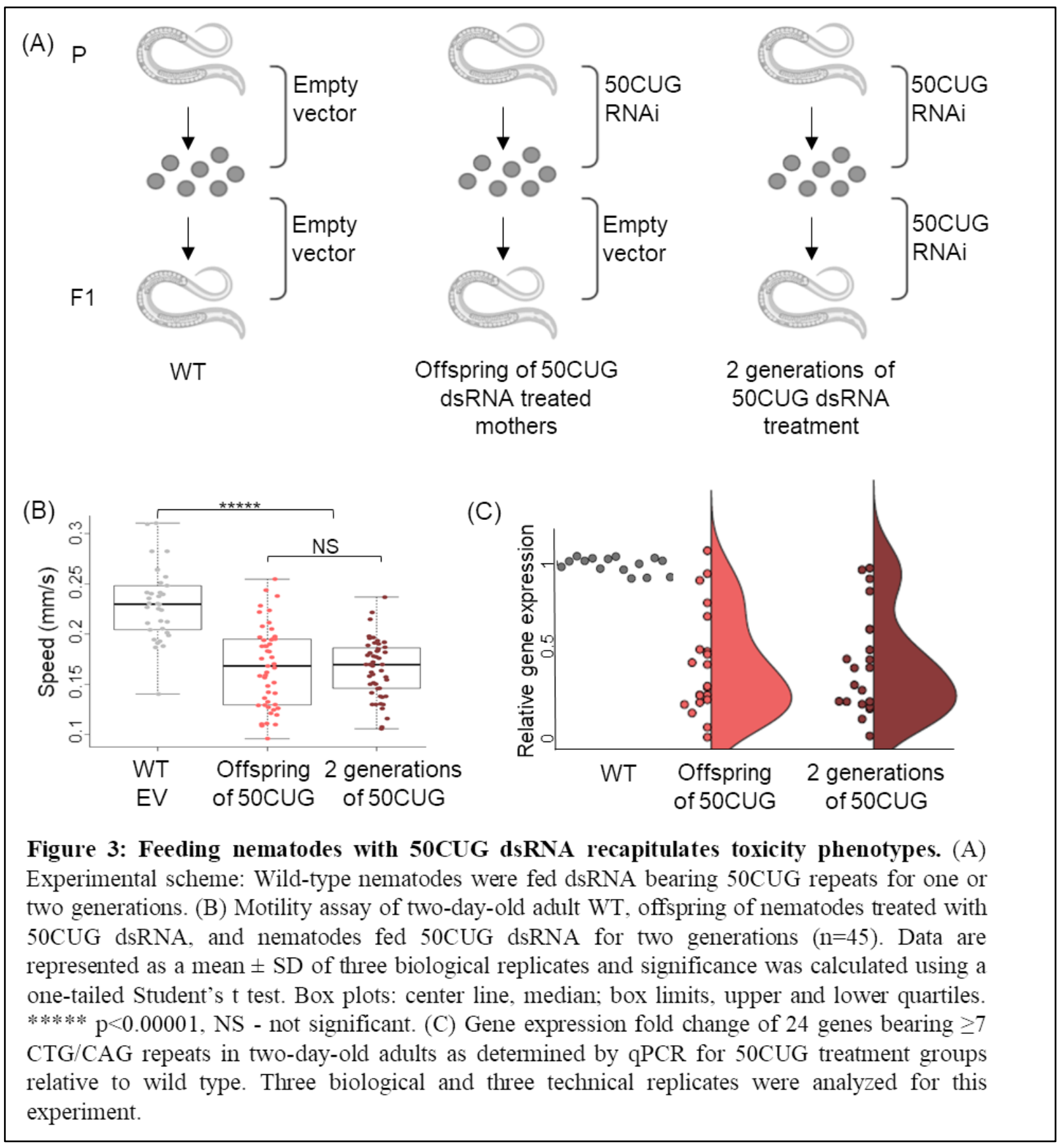




\section{Altering the RNAi machinery rescues toxicity in offspring with maternally inherited repeats}

As both the 50CUG dsRNA and the integrated $123 \mathrm{CUG}$ repeats had a toxic effect on P0 and F1 generations, we tested whether motility defects, sensitivity to stress, and downregulation of the 24 target genes could be rescued. Specifically, we considered that if the RNAi machinery plays a central role in the toxicity effect observed in maternal versus paternal inheritance, then disruption of the RNAi pathway has the potential to revert the phenotypes in the F1 progeny and affect the differences in toxicity between maternal and paternal inheritance.

As knocking out key players in the RNAi machinery can cause severe phenotypes in nematodes and other animals ${ }^{78,79}$, we used RNAi to regulate components in the RNAi machinery. This well-validated approach partly silences proteins in the pathway, thus affecting the steady state of the RNAi machinery, but generally with limited effects on phenotype ${ }^{31,37}$. Complete knockout of $d c r-1$ and $r d e-4$ RNAi resulted in severely impaired animals (Fig. 4S) whereas knockdown using $\mathrm{RNAi}^{31,37}$ did not produce an obvious detrimental effect (Fig. 4, 5S). Consequently, Maternal 123CUG (offspring of 123CUG mothers) were treated with RNAi against key members in siRNA production: $d c r-1, r d e-4$, and $r d e-1$ (Fig. 4A). The treated Maternal 123CUG nematodes exhibited rescued motility, with speeds corresponding to an average of $0.22 \mathrm{~mm} / \mathrm{s}$ following treatment of $d c r-1, r d e-1$, and $r d e-4$ RNAi as compared to the empty vector (Fig. 4B, 5S). Treated Maternal $123 \mathrm{CUG}$ animals also exhibited improved heat shock response, with approximately $90 \%$ survival rates after six hours in $35^{\circ} \mathrm{C}$ as compared with $60 \%$ of Maternal $123 \mathrm{CUG}$ and $70 \%$ of Paternal 123CUG animals (Fig. 4C). Next, we used qPCR to assess the effect of RNAi treatment on the expression of the targeted CTG/CAGbearing genes. We observed a 4-fold reduction in expression of targeted genes in the Maternal 123CUG group as compared to a reduction of approximately 1.3 -fold following treatment with $d c r-1, r d e-1$, and $r d e-4$ RNAi in Maternal 123CUG animals. In sum, RNAi treatment suppressed the phenotype at the molecular level and partly rescued down-regulation of the CTG/CAG-bearing genes (Fig. 4D). In comparison with the Maternal 123CUG group, an average of a $120 \%$ increase in GFP intensity was observed in the $d c r-1, r d e-1$, and $r d e-4$ RNAi treatment groups (Fig. 4E, 6S). Notably, fluorescence levels after treatment were similar to the Paternal 123CUG group levels. Together these data support, for the first time, the role of siRNAs as the underlying mechanism in the parent-of-origin effect. Furthermore, they demonstrate that regulation of this pathway can rescue both molecular and organism level phenotypes of maternally inherited toxicity, as observed in Maternal 123CUG animals. 
bioRxiv preprint doi: https://doi.org/10.1101/2021.05.19.444826; this version posted May 19, 2021. The copyright holder for this preprint (which was not certified by peer review) is the author/funder, who has granted bioRxiv a license to display the preprint in perpetuity. It is made available under aCC-BY-NC-ND 4.0 International license.

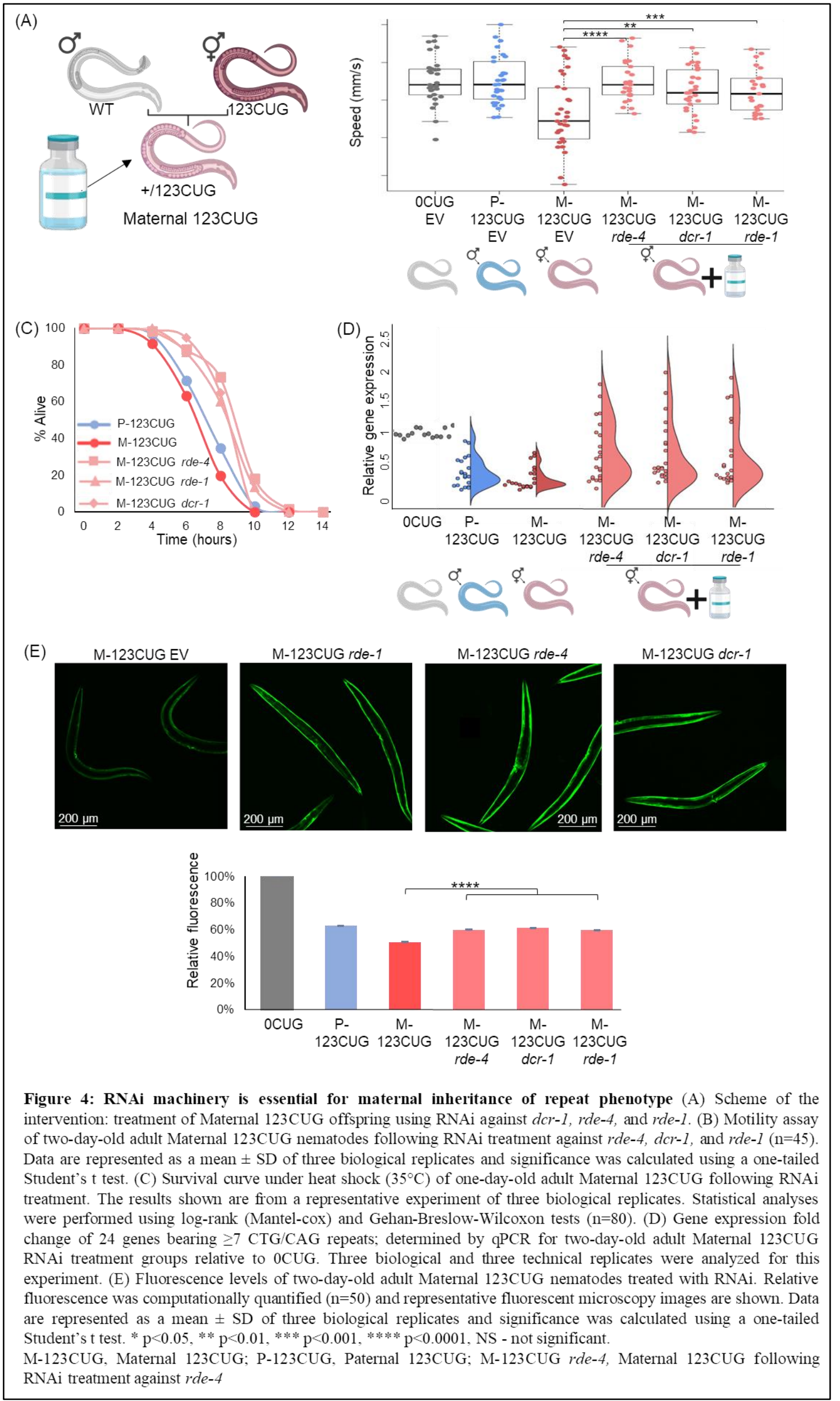




\section{Reducing activity of essential RNAi machinery components in 123CUG hermaphrodites rescues toxicity in offspring}

Enhancement of silencing is dependent on repeats being generated in the mothers either by feeding or expression of a transgene (Figs. 1-3). Consequently, we checked whether silencing the RNAi machinery has cross-generational effects. Epigenetic inheritance of small RNA is established $^{58,61,70}$, but a role for this inheritance in RNA toxicity or a link to expanded repeats is unknown, as well as its potential therapeutic impact in this context. Thus, we tested if perturbing the siRNA production only in the 123CUG mothers reduced the toxic phenotype in offspring expressing 123CUG. We fed 123CUG hermaphrodites RNAi against rde-1, rde-4, and $d c r-1$ to reduce processing of toxic RNAs into siRNAs. At the $4^{\text {th }}$ larval stage, we removed the hermaphrodites from the RNAi plates, crossed them with wild type males on EV plates, and assessed the offspring for effects on motility, heat shock, fluorescence, and changes in targeted gene expression (Fig. 5). Timing the RNAi feeding restricted the silencing of the RNAi machinery components (either $r d e-1, r d e-4$, and $d c r-1$ ) to the 123CUG parent hermaphrodites ${ }^{64}$. We observed that the progeny of $123 \mathrm{CUG}$ mothers with suppressed RNAi machinery displayed a significant improvement in movement with an average speed of 0.22 $\mathrm{mm} / \mathrm{s}$, as compared to $0.186 \mathrm{~mm} / \mathrm{s}$ in Maternal $123 \mathrm{CUG}$ (Fig. 5B, 7S). A significant improvement in response to heat stress was also observed (Fig. 5C). Expression levels of CTG/CAG-bearing genes were up-regulated in the offspring of the treated mothers, from a down-regulation of 4-fold in Maternal 132CUG to 1.6-fold, and 1.3-fold in offspring of rde-1 and $r d e-4$ RNAi treated mothers, reaching wild type levels following treatment against $d c r-1$ in hermaphrodites (Fig. 5D). This trend was also mirrored by the fluorescence assay as fluorescence levels were on average $171 \%$ higher in the offspring of $r d e-1, r d e-4$, and $d c r-1$ treated Maternal 123CUG nematodes in comparison to Maternal 123CUG animals (Fig. 5E). Importantly, there was no effect observed on the fluorescence levels of offspring of treated Paternal 123CUG nematodes (Fig. 8S). To conclude, down-regulating siRNA production in 123CUG hermaphrodites rescued pathogenic phenotypes in their offspring (Maternal 123CUG), but analogous treatment of 123CUG males did not affect their offspring (Paternal 123CUG). Together, these results indicate a possible treatment venue for repeat expansion disorders. 
bioRxiv preprint doi: https://doi.org/10.1101/2021.05.19.444826; this version posted May 19, 2021. The copyright holder for this preprint (which was not certified by peer review) is the author/funder, who has granted bioRxiv a license to display the preprint in perpetuity. It is made available under aCC-BY-NC-ND 4.0 International license.
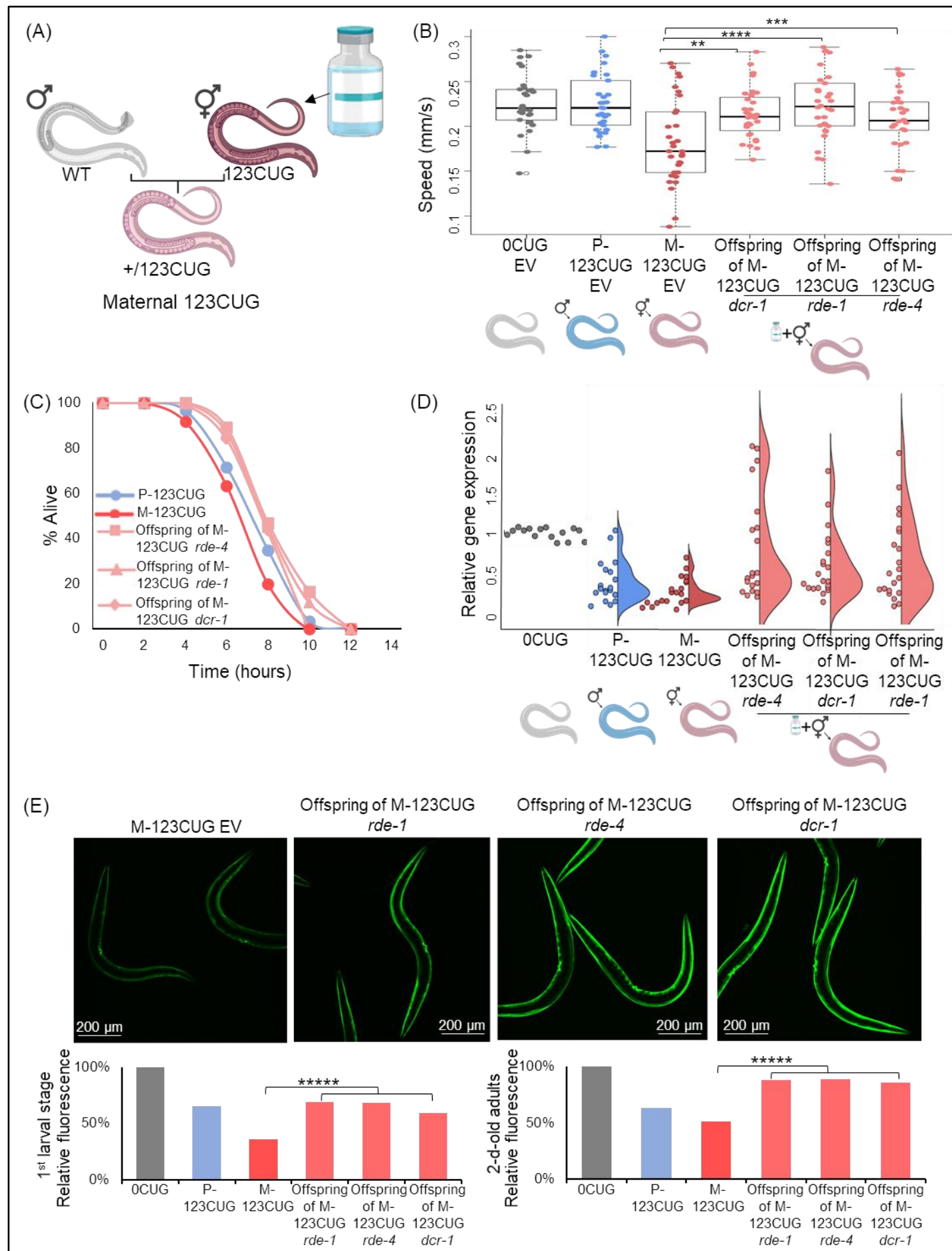

Figure 5: Exclusive treatment of affected 123CUG mothers rescues phenotype in offspring with maternally inherited repeats. (A) Scheme of the intervention: treatment of 123CUG hermaphrodites using RNAi against dcr-1, $r d e-4$, and $r d e-1$, until the $4^{\text {th }}$ larval stage, followed by mating with $\mathrm{N} 2$ males to create Maternal $123 \mathrm{CUG}$ animals. Offspring were observed for phenotypic effects. (B) Motility assay of two-day-old adult progeny of mothers treated against $r d e-4, d c r-1$, and $r d e-1 \quad(\mathrm{n}=45)$. Data are represented as a mean $\pm \mathrm{SD}$ of three biological replicates and significance was calculated using a one-tailed Student's $t$ test. (C) Survival curve under heat shock $\left(35^{\circ} \mathrm{C}\right.$ ) of one-dayold adult progeny of treated mothers. The results shown are from a representative experiment of three biological replicates. Statistical analysis was performed using log-rank (Mantel-cox) and Gehan-Breslow-Wilcoxon tests ( $\mathrm{n}=80$ ). (D) Gene expression fold change of 24 genes bearing $\geq 7 \mathrm{CTG} / \mathrm{CAG}$ repeats; determined by qPCR for offspring following RNAi treatment to mothers, relative to $0 \mathrm{CUG}$. Three biological and three technical replicates were analyzed for this experiment. (E) Fluorescence levels of $2^{\text {nd }}$ larval stage and two-day-old adult Maternal $123 \mathrm{CUG}$ offspring subsequent RNAi treatment of mothers. Relative fluorescence was computationally quantified $(n=50)$. Representative fluorescent microscopy images of two-day-old adults are shown. Data are represented as a mean $\pm \mathrm{SD}$ of three biological replicates and significance was calculated using a one-tailed Student's $t$ test. $* * \mathrm{p}<0.01, * * * \mathrm{p}<0.001, * * * *$ $\mathrm{p}<0.0001$, NS - not significant. M-123CUG, Maternal 123CUG; P-123CUG, Paternal 123CUG 


\section{Discussion}

We offer a new mechanism for the intergenerational toxicity of CUG repeats. We demonstrated how the repeated RNAs can cause maternal bias through the RNA machinery. This led to our ability to rescue most of the disease phenotypes in offspring by targeting the RNAi machinery in the mothers. Overall, we characterized in C. elegans a complex molecular crosstalk between DNA repeats, RNA toxicity, and the RNAi machinery in gender-specific toxicity inheritance, and its consequences to disease onset and progression. We showed that the maternal bias associated with expanded CTG repeats is mediated by intergenerational transmission of maternal repeat-derived siRNAs that initiate early alterations in gene expression.

Generally, the parent-of-origin effect is grossly attributed to three possible mechanisms: epigenetic regulation of gene expression, mitochondrial genome mutations, and the maternal intrauterine environment ${ }^{9}$. While a global mechanism underlying the parent-of-origin effect in repeat expansion disorders remains unelucidated, several explanations have been proposed for the maternal bias in congenital DM1: hypermethylation upstream to the expanded repeats that alters the expression of the downstream SIX5 gene, and longer repeat expansions leading to increased disruption of MBNL activity ${ }^{21,27,80,81}$. SIX5 loss of function in model mice did not recapitulate congenital DM1 phenotypes ${ }^{82}$. Mbnll;Mbnl2;Mbnl3 triple-knockout mice have shown congenital myopathy, respiratory insufficiency, and perinatal lethality ${ }^{81}$. However, the correlation is limited between a larger expansion of repeats leading to increased RNA toxicity and manifestation of congenital DM1 ${ }^{14}$. Therefore, additional mechanisms are expected to contribute to the maternal bias in CDM1 pathogenesis.

Here we established an isogenic animal system to study repeat-induced toxicity across generations. C. elegans are ideal to study epigenetic inheritance $58,60,83$ and the RNAi machinery ${ }^{29,32,34,35,37-42}$ in a well-controlled background. While our work uses C. elegans, the phenotypic similarity and the conservation of the RNAi machinery across eukaryotes ${ }^{31}$ suggests that homologous mechanisms can be found in other species. While further studies are needed to confirm the mechanism in mammals, cell lines are inappropriate for investigation of parental environment impact on progeny.

To dissect the RNA toxicity effect, we expressed 123CUG repeats endogenously, isolated from its gene context, and in addition examined the effect directly using repeat dsRNA (which we denoted as 50CUG). We found that expanded CUG repeats induced RNA toxicity with 
maternal biases and that this effect was dependent on the RNAi machinery (Fig. 6). We found elevated expression of small repeat RNA and coordinated suppression of genes with complementary sequences in both Maternal 123CUG (offspring of 123CUG mothers) and Paternal 123CUG (offspring of 123CUG fathers) animals, with enhanced suppression in the Maternal 123CUG group. In addition, the phenotypes associated with toxicity were asymmetrically inherited and enhanced in the Maternal 123CUG animals. Altering fundamental RNAi machinery members rescued the disease phenotypes and up-regulated the expression of affected genes. Moreover, down-regulating key members in siRNA production exclusively in the affected hermaphrodites rescued all the molecular and organismal phenotypes in the untreated offspring. These data imply that the parent-of-origin effect is mediated by maternal repeat-derived siRNAs that enhance early gene silencing in their progeny. These results point to a potential therapeutic approach for repeat-carrying mothers to ameliorate disease phenotype in progeny.

Regarding the limitations of the 123CUG system, it could be argued that the repetitive arrays are independently targeted by the RNAi machinery and processed into siRNAs. However, the recapitulation of disease phenotype achieved by directly feeding 50CUG dsRNA to nematodes, together with the rescue effect following perturbation of $d c r-1, r d e-1$, and $r d e-4$, strongly support the role of Dicer in mediating the toxic siRNA production. Importantly, the control data obtained from the OCUG strain show that the maternal bias is specific to the expanded CUG repeats and is absent in the control 0CUG strain (Fig. 2B, 2S). Therefore, if transgene silencing contributes to siRNA production, it is assumed to be negligible, but nevertheless augments the desirable outcome of recapitulating the pathologic siRNAs found in patient cells.

The human genome consists of over 800 genes bearing endogenous 6CTG repeats that may serve as potential targets for siRNA silencing. Among these genes are numerous transcription factors, whose alteration may trigger extensive changes in gene expression, affecting various tissues. Future work analyzing patient transcriptome in affected tissues may shed light on unanswered questions in disease pathology. Our suggested mechanism, if recapitulated in mammals, has the potential to explain several phenotypes associated with congenital DM1 as well as other expansion repeat disorders that exhibit prominent maternal biases ${ }^{7,8}$. We highlight the embryonic environment as a major contributor to the aggravated phenotype associated with maternal transmission. In humans, endogenous RNAi activity was reported in both germline and somatic cells ${ }^{84-86}$, although the interferon pathway is considered the main responder to dsRNA. Substantial evidence indicates that small RNAs originated from the mother can 
infiltrate the embryo and overtime effect global gene expression ${ }^{71,87-89}$. We hypothesize that the affected progeny may be continuously exposed to additional repeat-derived siRNAs during pregnancy. This may also explain the obscure disease course. Once the newborn overcomes the intensified RNA toxicity, the symptoms improve until the accumulative damage caused by the additional established RNA toxicity mechanisms is sufficient to produce classical DM1 symptoms. Importantly, the Maternal 123CUG nematodes exhibit evident maternal toxicity without anticipation of repeat length. Our suggested mechanism of maternally inherited toxicity suggests that repeat-carrying mothers may affect both sick and healthy progeny. Intriguingly, even healthy offspring born to DM1 mothers following pre-implantation genetic diagnosis presented a relatively high incidence of minor anomalies ${ }^{90}$. While this may be a result of existing medical problems in the DM1 mothers, our data suggest that siRNAs may play a role. The repeat siRNAs from the mother trigger abnormal gene silencing in these offspring, but the effect is moderate due to the lack of self-repeats. While maternal biases were characterized in DM1 and spinocerebellar ataxia type $8^{7}$, future research should investigate additional non-coding repeat expansion disorders. Moreover, such studies should evaluate the role of RNA interference in other disorders exhibiting parent-of-origin effects.

To conclude, we offer a novel mechanism of toxicity inheritance in repeat-based disorders. Our experimental data suggest that RNAi machinery may play a key role in the parent-of-origin effect and can transmit toxicity from parent to child, mediate disease pathogenesis, and explain the maternal bias. Consequently, it provides an opportunity to develop novel disease-modifying therapeutics for DM1 and possibly other expansion repeat disorders. 
bioRxiv preprint doi: https://doi.org/10.1101/2021.05.19.444826; this version posted May 19, 2021. The copyright holder for this preprint (which was not certified by peer review) is the author/funder, who has granted bioRxiv a license to display the preprint in perpetuity. It is made available under aCC-BY-NC-ND 4.0 International license.

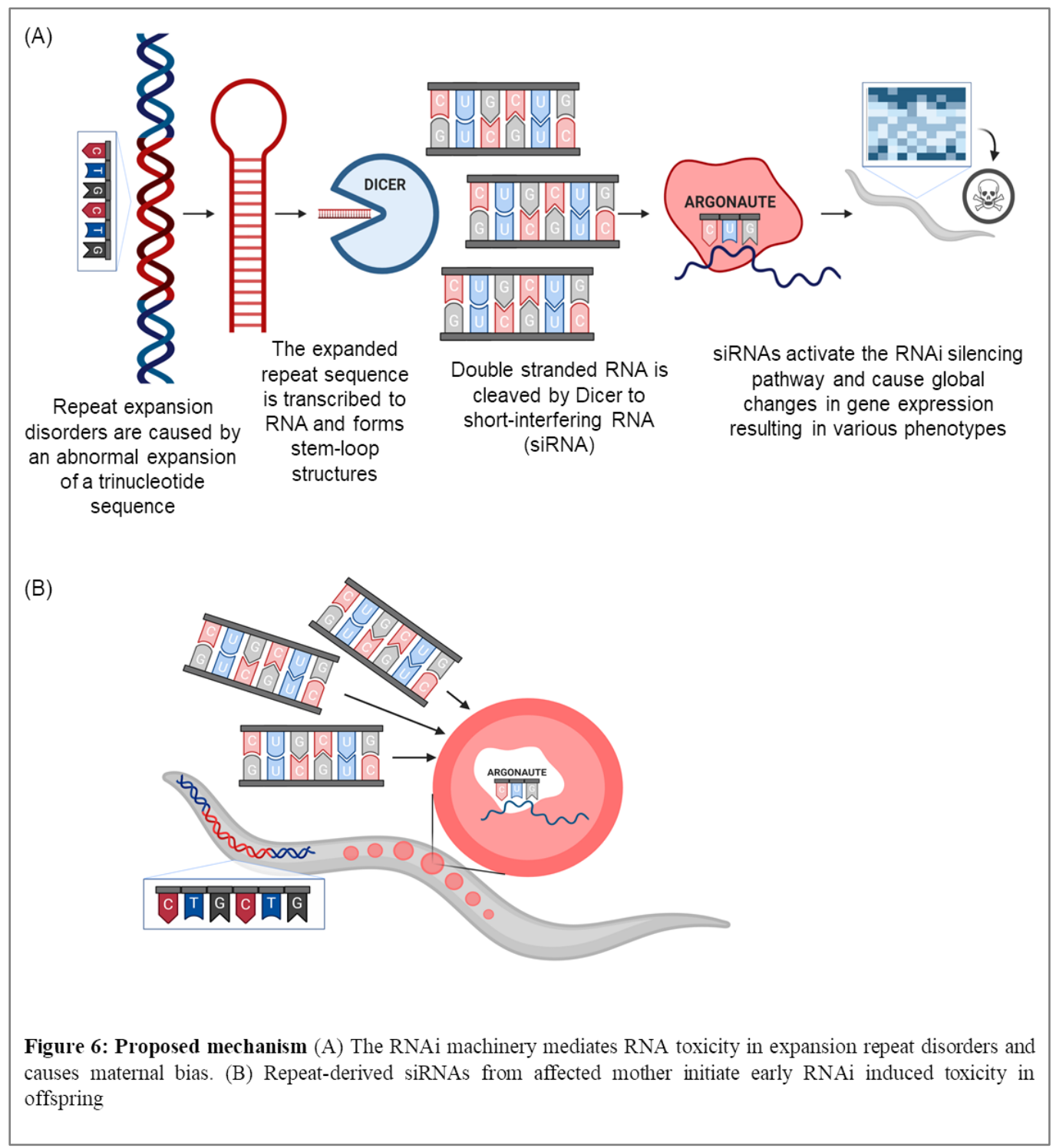


bioRxiv preprint doi: https://doi.org/10.1101/2021.05.19.444826; this version posted May 19, 2021. The copyright holder for this preprint (which was not certified by peer review) is the author/funder, who has granted bioRxiv a license to display the preprint in perpetuity. It is made available under aCC-BY-NC-ND 4.0 International license.

\section{References}

1. Paulson, H. \& Arbor, A. Repeat Expansion Diseases. Encyclopedic Reference of Genomics and Proteomics in Molecular Medicine (2006). doi:10.1007/3-540-29623-9_8503

2. Daughters, R. S. et al. RNA gain-of-function in spinocerebellar ataxia type 8. PLoS Genet. 5, (2009).

3. Davis, B. M., Mccurrach, M. E., Taneja, K. L., Singer, R. H. \& Housman, D. E. Expansion of a CUG trinucleotide repeat in the $3^{\prime}$ untranslated region of myotonic dystrophy protein kinase transcripts results in nuclear retention of transcripts. Proc. Natl. Acad. Sci. U. S. A. 94, (1997).

4. Taneja, K. L., McCurrach, M., Schalling, M., Housman, D. \& Singer, R. H. Foci of trinucleotide repeat transcripts in nuclei of myotonic dystrophy cells and tissues. J. Cell Biol. 128, (1995).

5. Swinnen, B. et al. A zebrafish model for C9orf72 ALS reveals RNA toxicity as a pathogenic mechanism. Acta Neuropathol. 135, (2018).

6. Swinnen, B., Robberecht, W. \& Van Den Bosch, L. RNA toxicity in non-coding repeat expansion disorders. EMBO J. 39, (2020).

7. Day, J. W., Schut, L. J., Moseley, M. L., Durand, A. C. \& Ranum, L. P. W. Spinocerebellar ataxia type 8 : Clinical features in a large family. Neurology 55, (2000).

8. Echenne, B. \& Bassez, G. Congenital and infantile myotonic dystrophy. in Handbook of Clinical Neurology 113, (2013).

9. Guilmatre, A. \& Sharp, A. J. Parent of origin effects. Clinical Genetics 81, (2012).

10. Ashizawa, T., Dunne, P. W., Ward, P. A., Seltzer, W. K. \& Richards, C. S. Effects of the sex of myotonic dystrophy patients on the unstable triplet repeat in their affected offspring. Neurology 44, (1994).

11. Harper, P. Myotonic dystrophy. Oxford University Press, Oxford, (2009).

12. Turner, C. \& Hilton-Jones, D. The myotonic dystrophies: diagnosis and management. doi:10.1136/jnnp.2008.158261

13. Ho, G. Congenital and childhood myotonic dystrophy: Current aspects of disease and future directions. World J. Clin. Pediatr. 4, (2015).

14. Lanni, S. \& Pearson, C. E. Molecular genetics of congenital myotonic dystrophy. Neurobiology of Disease 132, (2019).

15. Harper, P. S. \& Dyken, P. R. Early-onset dystrophia myotonica supporting a maternal environmental factor. Lancet 300, (1972).

16. Koch, M. C., Grimm, T., Harley, H. G. \& Harper, P. S. Genetic risks for children of women with myotonic dystrophy. Am. J. Hum. Genet. 48, (1991).

17. De Rademaeker, M. et al. Preimplantation genetic diagnosis for myotonic dystrophy type 1: Upon request to child. Eur. J. Hum. Genet. 17, (2009).

18. Fernández, R. M. et al. Preimplantation genetic diagnosis for myotonic dystrophy type 1 and analysis of the effect of the disease on the reproductive outcome of the affected female patients. Biomed Res. Int. 2017, (2017).

19. Margolis, R. L., Rudnicki, D. D. \& Holmes, S. E. Huntington's disease like-2: Review and update. Acta Neurologica Taiwanica 14, (2005).

20. Schneider, S. A., Marshall, K. E., Xiao, J. \& LeDoux, M. S. JPH3 repeat expansions cause a progressive akinetic-rigid syndrome with severe dementia and putaminal rim in a fivegeneration African-American family. Neurogenetics 13, (2012).

21. Barbé, L. et al. CpG methylation, a parent-of-origin effect for maternal-biased transmission of congenital myotonic dystrophy. Am. J. Hum. Genet. 100, (2017).

22. Rudnik-Schöneborn, S., Nicholson, G. A., Morgan, G., Röhrig, D. \& Zerres, K. Different patterns of obstetric complications in myotonic dystrophy in relation to the disease status of the fetus. Am. J. Med. Genet. 80, (1998).

23. Thyagarajan, D. et al. Mitochondrial DNA sequence analysis in congenital myotonic dystrophy. Ann. Neurol. 30, (1991).

24. Poulton, J. et al. Mitochondrial DNA does not appear to influence the congenital onset type of myotonic dystrophy. J. Med. Genet. 32, (1995).

25. Cobo, A. M. et al. Contribution of molecular analyses to the estimation of the risk of congenital myotonic dystrophy. J. Med. Genet. 32, (1995).

26. Morales, F. et al. Parental age effects, but no evidence for an intrauterine effect in the transmission of myotonic dystrophy type 1. Eur. J. Hum. Genet. 23, (2015). 
bioRxiv preprint doi: https://doi.org/10.1101/2021.05.19.444826; this version posted May 19, 2021. The copyright holder for this preprint (which was not certified by peer review) is the author/funder, who has granted bioRxiv a license to display the preprint in perpetuity. It is made available under aCC-BY-NC-ND 4.0 International license.

27. Yanovsky-Dagan, S. et al. Uncovering the role of hypermethylation by CTG expansion in myotonic dystrophy type 1 using mutant human embryonic stem cells. Stem Cell Reports $\mathbf{5}$, (2015).

28. Fire, A. et al. Potent and specific genetic interference by double-stranded RNA in caenorhabditis elegans. Nature 391, (1998).

29. Tabara, H. et al. The rde-1 gene, RNA interference, and transposon silencing in C. elegans. Cell 99, (1999).

30. Fagard, M., Boutet, S., Morel, J. B., Bellini, C. \& Vaucheret, H. AGO1, QDE-2, and RDE-1 are related proteins required for post-transcriptional gene silencing in plants, quelling in fungi, and RNA interference in animals. Proc. Natl. Acad. Sci. U. S. A. 97, (2000).

31. Tabach, Y. et al. Identification of small RNA pathway genes using patterns of phylogenetic conservation and divergence. Nature (2013). doi:10.1038/nature11779

32. Ketting, R. F. et al. Dicer functions in RNA interference and in synthesis of small RNA involved in developmental timing in C. elegans. Genes Dev. 15, (2001).

33. Bernstein, E., Caudy, A. A., Hammond, S. M. \& Hannon, G. J. Role for a bidentate ribonuclease in the initiation step of RNA interference. Nature 409, (2001).

34. Knight, S. W. \& Bass, B. L. A role for the RNase III enzyme DCR-1 in RNA interference and germ line development in Caenorhabditis elegans. Science (80-. ). 293, (2001).

35. Grishok, A. et al. Genes and mechanisms related to RNA interference regulate expression of the small temporal RNAs that control C. elegans developmental timing. Cell 106, (2001).

36. Hammond, S. M. Dicing and slicing: the core machinery of the RNA interference pathway. FEBS Lett. 579, 5822-9 (2005).

37. Kim, J. K. et al. Functional genomic analysis of RNA interference in C. elegans. Science (80-. ). 308, (2005).

38. Fischer, S. E. J., Butler, M. D., Pan, Q. \& Ruvkun, G. Trans-splicing in C. elegans generates the negative RNAi regulator ERI-6/7. Nature 455, (2008).

39. Timmons, L. \& Fire, A. Specific interference by ingested dsRNA [10]. Nature (1998). doi:10.1038/27579

40. Ketting, R. F., Haverkamp, T. H. A., Van Luenen, H. G. A. M. \& Plasterk, R. H. A. mut-7 of C. elegans, required for transposon silencing and RNA interference, is a homolog of werner syndrome helicase and RNaseD. Cell 99, (1999).

41. Grishok, A., Tabara, H. \& Mello, C. C. Genetic requirements for inheritance of RNAi in C. elegans. Science (80-. ). 287, (2000).

42. Sijen, T. et al. On the role of RNA amplification in dsRNA-triggered gene silencing. Cell 107, (2001).

43. Tabara, H., Yigit, E., Siomi, H. \& Mello, C. C. The dsRNA binding protein RDE-4 interacts with RDE-1, DCR-1, and a DExH-Box helicase to direct RNAi in C. elegans. Cell 109, (2002).

44. Rzeszutek, I. \& Singh, A. Small RNAs, big diseases. International Journal of Molecular Sciences 21, (2020).

45. Martí, E. \& Estivill, X. Small non-coding RNAs add complexity to the RNA pathogenic mechanisms in trinucleotide repeat expansion diseases. Front. Mol. Neurosci. (2013). doi:10.3389/fnmol.2013.00045

46. Sun, B. K. \& Tsao, H. Small RNAs in development and disease. Journal of the American Academy of Dermatology 59, (2008).

47. Qawasmi, L. et al. Expanded CUG repeats trigger disease phenotype and expression changes through the RNAi machinery in C. elegans. J. Mol. Biol. (2019). doi:10.1016/j.jmb.2019.03.003

48. Yu, Z., Teng, X. \& Bonini, N. M. Triplet repeat-derived siRNAs enhance RNA-mediated toxicity in a Drosophila model for myotonic dystrophy. PLoS Genet. 7, e1001340 (2011).

49. Murmann, A. E. et al. Small interfering RNA s based on huntingtin trinucleotide repeats are highly toxic to cancer cells . EMBO Rep. 19, (2018).

50. Krol, J. et al. Ribonuclease dicer cleaves triplet repeat hairpins into shorter repeats that silence specific targets. Mol. Cell (2007). doi:10.1016/j.molcel.2007.01.031

51. Cappella, M. et al. High-throughput analysis of the RNA-induced silencing complex in myotonic dystrophy type 1 patients identifies the dysregulation of miR-29c and its target ASB2. Cell Death Dis. 9, (2018).

52. Garcia, S. M. D. A., Tabach, Y., Lourenço, G. F., Armakola, M. \& Ruvkun, G. Identification of 
bioRxiv preprint doi: https://doi.org/10.1101/2021.05.19.444826; this version posted May 19, 2021. The copyright holder for this preprint (which was not certified by peer review) is the author/funder, who has granted bioRxiv a license to display the preprint in perpetuity. It is made available under aCC-BY-NC-ND 4.0 International license.

genes in toxicity pathways of trinucleotide-repeat RNA in C. elegans. Nat. Struct. Mol. Biol. 21, 712-20 (2014).

53. Kumar, V., Hasan, G. M. \& Hassan, M. I. Unraveling the role of RNA mediated toxicity of C9orf72 repeats in C9-FTD/ALS. Frontiers in Neuroscience 11, (2017).

54. Mizielinska, S. et al. C9orf72 frontotemporal lobar degeneration is characterised by frequent neuronal sense and antisense RNA foci. Acta Neuropathol. 126, (2013).

55. Bañez-Coronel, M. et al. A pathogenic mechanism in huntington's disease involves small CAGrepeated RNAs with neurotoxic activity. PLoS Genet. 8, (2012).

56. Rué, L. et al. Targeting CAG repeat RNAs reduces Huntington's disease phenotype independently of huntingtin levels. J. Clin. Invest. 126, (2016).

57. Ewe, C. K. et al. Natural cryptic variation in epigenetic modulation of an embryonic gene regulatory network. Proc. Natl. Acad. Sci. U. S. A. 117, (2020).

58. Houri-Zeevi, L. \& Rechavi, O. A matter of time: small RNAs regulate the duration of epigenetic inheritance. Trends in Genetics 33, (2017).

59. Shirayama, M. et al. PiRNAs initiate an epigenetic memory of nonself RNA in the C. elegans germline. Cell 150, (2012).

60. Rechavi, O., Minevich, G. \& Hobert, O. Transgenerational inheritance of an acquired small RNA-based antiviral response in C. elegans. Cell 147, (2011).

61. Rechavi, O. \& Lev, I. Principles of transgenerational small RNA inheritance in Caenorhabditis elegans. Current Biology 27, (2017).

62. Alcazar, R. M., Lin, R. \& Fire, A. Z. Transmission dynamics of heritable silencing induced by double-stranded RNA in Caenorhabditis elegans. Genetics 180, (2008).

63. Buckley, B. A. et al. A nuclear Argonaute promotes multigenerational epigenetic inheritance and germline immortality. Nature 489, (2012).

64. Marré, J., Traver, E. C. \& Jose, A. M. Extracellular RNA is transported from one generation to the next in Caenorhabditis elegans. Proc. Natl. Acad. Sci. U. S. A. 113, (2016).

65. Ashe, A. et al. PiRNAs can trigger a multigenerational epigenetic memory in the germline of C. elegans. Cell 150, (2012).

66. Gu, S., Jin, L., Huang, Y., Zhang, F. \& Kay, M. A. Slicing-independent RISC activation requires the argonaute PAZ domain. Curr. Biol. 22, (2012).

67. Luteijn, M. J. et al. Extremely stable Piwi-induced gene silencing in Caenorhabditis elegans. EMBO J. 31, (2012).

68. Perales, R. et al. Transgenerational epigenetic inheritance is negatively regulated by the HERI1 chromodomain protein. Genetics 210, (2018).

69. Lev, I. et al. Germ granules govern small RNA inheritance. Curr. Biol. 29, (2019).

70. Lev, I. \& Rechavi, O. Germ granules allow transmission of small RNA-based parental responses in the germ plasm. iScience 23, 101831 (2020).

71. Li, J. et al. Small non-coding RNAs transfer through mammalian placenta and directly regulate fetal gene expression. Protein Cell 6, (2015).

72. $\mathrm{Su}, \mathrm{Z}$. et al. tRNA-derived fragments and microRNAs in the maternal-fetal interface of a mouse maternal-immune-activation autism model. RNA Biol. 17, (2020).

73. Miura, K. et al. Identification of pregnancy-associated microRNAs in maternal plasma. Clin. Chem. 56, (2010).

74. Luo, J. et al. The pro-angiogenesis of exosomes derived from umbilical cord blood of intrauterine growth restriction pigs was repressed associated with MiRNAs. Int. J. Biol. Sci. 14, (2018).

75. Ouyang, Y., Mouillet, J. F., Coyne, C. B. \& Sadovsky, Y. Review: Placenta-specific microRNAs in exosomes - Good things come in nano-packages. Placenta 35, (2014).

76. Chen, K. Y. et al. Length-dependent toxicity of untranslated CUG repeats on Caenorhabditis elegans. Biochem. Biophys. Res. Commun. (2007). doi:10.1016/j.bbrc.2006.11.102

77. Simmer, F. et al. Loss of the putative RNA-directed RNA polymerase RRF-3 makes C. Elegans hypersensitive to RNAi. Curr. Biol. 12, (2002).

78. Fischer, S. E. J. et al. Multiple small RNA pathways regulate the silencing of repeated and foreign genes in C. elegans. Genes Dev. 27, (2013).

79. Denli, A. M., Tops, B. B. J., Plasterk, R. H. A., Ketting, R. F. \& Hannon, G. J. Processing of primary microRNAs by the Microprocessor complex. Nature 432, (2004). 
80. Steinbach, P., Gläser, D., Vogel, W., Wolf, M. \& Schwemmle, S. The DMPK gene of severely affected myotonic dystrophy patients is hypermethylated proximal to the largely expanded CTG repeat. Am. J. Hum. Genet. 62, (1998).

81. Thomas, J. D. et al. Disrupted prenatal RNA processing and myogenesis in congenital myotonic dystrophy. Genes Dev. 31, (2017).

82. Matynia, A. et al. Muscleblind1, but not Dmpk or Six5, contributes to a complex phenotype of muscular and motivational deficits in mouse models of Myotonic Dystrophy. PLoS One 5, (2010).

83. Houri-Ze'evi, L. \& Rechavi, O. Plastic germline reprogramming of heritable small RNAs enables maintenance or erasure of epigenetic memories. RNA Biology 13, (2016).

84. Svoboda, P. Renaissance of mammalian endogenous RNAi. FEBS Letters 588, (2014).

85. Diallo, M., Arenz, C., Schmitz, K., Sandhoff, K. \& Schepers, U. Long endogenous dsRNAs can induce complete gene silencing in mammalian cells and primary cultures. Oligonucleotides $\mathbf{1 3}$, (2003).

86. Yi, C. E., Bekker, J. M., Miller, G., Hill, K. L. \& Crosbie, R. H. Specific and potent RNA interference in terminally differentiated myotubes. J. Biol. Chem. 278, (2003).

87. Gross, N., Kropp, J. \& Khatib, H. MicroRNA signaling in embryo development. Biology 6, (2017).

88. Ng, Y. H. et al. Endometrial exosomes/microvesicles in the uterine microenvironment: a new paradigm for embryo-endometrial cross talk at implantation. PLoS One 8, (2013).

89. Vilella, F. et al. Hsa-miR-30d, secreted by the human endometrium, is taken up by the preimplantation embryo and might modify its transcriptome. Dev. 142, (2015).

90. Martorell, L. et al. Prenatal diagnosis in myotonic dystrophy type 1. Thirteen years of experience: Implications for reproductive counselling in DM1 families. Prenat. Diagn. 27, (2007).

91. Stiernagle, T. Maintenance of C. elegans. WormBook: the online review of C. elegans biology (2006). doi:10.1895/wormbook.1.101.1

92. Kamath, R. S., Martinez-Campos, M., Zipperlen, P., Fraser, A. G. \& Ahringer, J. Effectiveness of specific RNA-mediated interference through ingested double-stranded RNA in Caenorhabditis elegans. Genome Biol. (2001). doi:10.1186/gb-2000-2-1-research0002

93. Altschul, S. F., Gish, W., Miller, W., Myers, E. W. \& Lipman, D. J. Basic local alignment search tool. J. Mol. Biol. (1990). doi:10.1016/S0022-2836(05)80360-2

\section{$\underline{\text { Methods }}$}

\section{C. elegans and RNAi strains}

C. elegans strains GR2024, GR3207 (123CUG) and GR2025, GR3208 (0CUG) were used ${ }^{52}$. These animals express $123 \mathrm{CUG}$ or 0CUG repeats in the 3'UTR of GFP in the body wall muscle cells under the myo-3 promoter. The N2 (Bristol) strain was obtained from the Caenorhabditis Genetics Center (Minneapolis, USA) and used as a wild-type strain. For the RNAi mutant assays, strains ne299 (rde-4), and PD8753 (dcr-1) were obtained from the Caenorhabditis Genetics Center. C. elegans strains were handled using standard methods and grown at $20^{\circ} \mathrm{C}$ unless otherwise indicated ${ }^{91}$.

\section{Crossing Maternal and Paternal 123CUG strains}

Ten 123CUG one-day-old males were put on a plate with four L4 wildtype hermaphrodites. Plates were synced after 48 hours, eggs were left to hatch overnight in M9, and L1 nematodes with Paternal 123CUG were produced. For Maternal 123CUG, the process was replicated with 
10 wildtype one-day-old males and four L4 123CUG hermaphrodites. To rule out the possibility of biased phenotypes due to self-mating of the hermaphrodites, the crosses were validated by two approaches: $~ 50 \%$ prevalence of males in the F1 offspring was assessed and randomly selected F1 animals were sequenced for presence of repeats.

\section{Gene inactivation}

RNAi-mediated gene inactivation was achieved by feeding nematodes bacterial strains expressing dsRNA as previously described ${ }^{92}$. RNAi clones were obtained from the Ahringer's library. A single colony of RNAi bacteria was grown overnight at $37^{\circ} \mathrm{C}$ in $\mathrm{LB}$ with $100 \mathrm{mg} / \mathrm{ul}$ ampicillin, and then seeded onto NGM plates with carbenicillin. Vector expression was induced by adding isopropyl $\beta$-D-thiogalactopyranoside (IPTG) for a final concentration of 0.5-1 mM directly over the bacterial lawn and left to dry for $24 \mathrm{~h}$. An empty L4440 vector (EV) was used as a negative control.

\section{Motility}

At day two, four, and six of adulthood, five $C$. elegans males were picked and placed on 60 mm NGM plates without food. The nematodes were left to recover for 20 minutes after which they were filmed. Over 15 animals were counted per experiment and the data from three biological replicates were combined. Images were captured using a digital microscope and Micam 4.0 Software. The resolution was 2048 x 1536 pixels and a total number of 120 frames were taken at a rate of 1 capture per second for 120 seconds. In each experiment, all images were captured with the same focus, on the same day, and at room temperature. The video was built by MakeAVi software with a playback rate of 15 frames per second. The animals were analyzed using Tracker 5.0 software by defining the tail of the animal as a point mass and manually tracking its position for each frame. The statistical analysis was performed using a one-tailed Student's t-test, $\alpha=0.05$.

\section{Stress assays}

Synchronized worm eggs were placed on NGM plates seeded with RNAi bacteria or OP50 (as indicated) and supplemented with $100 \mathrm{mM}$ IPTG (4 mM final concentration). For the heat shock assay, at day one of adulthood 80 animals were transferred onto pre-warmed plates without bacteria (10 animals per plate) and exposed to $34-35^{\circ} \mathrm{C}$. Survival rates were recorded every two h. Statistical analyses was performed using log-rank (Mantel-cox) and GehanBreslow-Wilcoxon tests, $\alpha=0.05$.

\section{Morphology and length}


Maternal and Paternal 123CUG animals were generated and left to hatch in M9 until the $1^{\text {st }}$ larval stage. Then they were placed on NGM plates seeded with OP50 and immediately imaged using a Nikon SMZ800N Microscope. After $72 \mathrm{~h}$, the nematodes were imaged once again. The nematodes' length was determined using the DeltaPix software. Statistical analyses were performed using a one-tailed Student's t-test, $\alpha=0.05$.

\section{Target genes for siRNA silencing}

A BLAST ${ }^{93}$ search was conducted to identify genes with seven or more CTG/CAG repeats and with no more than two mismatches, that could serve as the most obvious targets for siRNA silencing. Thirty-one transcripts were identified and specific primers for 24 of those genes were generated. Expression levels were determined using RT-qPCR as described below. We were unable to generate specific primers and establish expression levels for the seven remaining genes.

\section{RT-qPCR analysis of mRNA and siRNA expression}

Total RNA was extracted from the whole body of C. elegans nematodes using Trizol Reagent (Ambion, USA) and a NucleoSpin RNA isolation kit (Macherey-Nagel, Germany). Hundreds of worms were collected for each experiment. For mRNA, reverse transcription was performed using a cDNA reverse transcription kit (Applied Biosystems, USA), and mRNA expression levels were measured with qPCR. SYBR-Green (Bio-Rad, USA) was used in a CFX-384 RealTime PCR system (Bio-Rad). For siRNA, reverse transcription was performed using the MystiCq miRNA cDNA synthesis Mix (Sigma Aldrich, USA). MystiCq SYBR green (SigmaAldrich) and universal PCR primer (Sigma-Aldrich) were used for RT-qPCR. Data were analyzed using the $\Delta \Delta \mathrm{Ct}$ method. Relative quantities of gene transcripts were normalized to $r p l-32$ and $c d c-42$ for the mRNAs, and mir-46-3p for the siRNAs. All the primers used in this research were designed using the NCBI Primer Blast (sequences depicted in Table 2S).

\section{Fluorescence}

Maternal 123CUG, Paternal 123CUG, and 0CUG nematodes were grown on empty vector bacteria and images were taken at the $1^{\text {st }}$ larval stage and two-day-old adults. The RNAi groups were treated as previously described and imaged at the same ages. The animals were washed twice with M9, anesthetized using $10 \mathrm{mM}$ sodium azide (Sigma Aldrich, USA), and placed on an agar pad. Images were taken using a Spinning-Disk confocal microscope. For all fluorescence images, the images shown within the same figure panel were collected using the same exposure time and then processed identically in ImageJ. Statistical analyses were performed using a one-tailed Student's t-test, $\alpha=0.05$. 


\section{Data availability}

The datasets generated during and/or analyzed during the current study are available from the corresponding authors on reasonable request.

\section{Acknowledgements}

We thank Prof. Gary Ruvkun, Massachusetts General Hospital and Harvard Medical School, for his comments on the project. We also thank Prof. Igor Ulitsky and Prof. Eran Hornstein at the Weizmann Institute of Science for reviewing the manuscript. Funding was received from the Israel Science Foundation (grant agreement 1591/19).

\section{Author contributions}

M.B. and Y.T. conceptualized the study and wrote the manuscript. M.B., S.S., J.T., A.M.S., and M.M. designed and carried out the experiments and analyzed the data. Z.G., S.E.J.F, S.M.D.A.G, and Y.T. edited the manuscript and supervised the research.

\section{The authors declare no competing interests.}

